\title{
The bile acid-sensitive ion channel (BASIC) mediates bile acid-dependent currents in bile duct epithelial cells
}

\author{
Shari Wiegreffe ${ }^{1} \cdot$ Daniel Löhrer $^{1} \cdot$ Monika Wirtz $^{1} \cdot$ Dominik Wiemuth $^{1}[$
}

Received: 21 February 2021 / Revised: 7 September 2021 / Accepted: 8 September 2021 / Published online: 21 September 2021

(c) The Author(s) 2021

\begin{abstract}
The bile acid-sensitive ion channel (BASIC) is a member of the Deg/ENaC family of ion channels that is activated by bile acids. Despite the identification of cholangiocytes in the liver and unipolar brush cells in the cerebellum as sites of expression, the physiological function of BASIC in these cell types is not yet understood. Here we used a cholangiocyte cell line, normal rat cholangiocytes (NRCs), which expresses BASIC to study the role of the channel in epithelial transport using Ussing chamber experiments. Apical application of bile acids induced robust and transient increases in transepithelial currents that were carried by $\mathrm{Na}^{+}$and partly blocked by the BASIC inhibitor diminazene. Genetic ablation of the BASIC gene in NRC using a CRISPR-cas9 approach resulted in a decrease of the bile acid-mediated response that matched the diminazenesensitive current in NRC WT cells, suggesting that cholangiocytes respond to bile acids with a BASIC-mediated $\mathrm{Na}^{+}$influx. Taken together, we have identified BASIC as a component of the cholangiocyte transport machinery, which might mediate a bile acid-dependent modification of the bile and thus control bile flux and composition.
\end{abstract}

Keywords Cholangiocyte $\cdot \mathrm{BASIC} \cdot \mathrm{Bile}$ acid $\cdot \mathrm{BLINaC} \cdot$ Cation channel $\cdot \mathrm{Deg} / \mathrm{ENaC}$

\section{Introduction}

The bile acid-sensitive ion channel (BASIC) is probably the least studied mammalian member of the degenerin/epithelial $\mathrm{Na}^{+}$channel (Deg/ENaC) family of ion channels [40]. Deg/ENaCs share several structural, electrophysiological, and pharmacological features [16]. Each channel consists of three subunits, which are composed of two transmembrane domains and linked by a large extracellular domain, $\mathrm{N}$-terminal and C-terminal domains protruding into the cytosol $[4,15]$. Deg/ENaCs are voltage-independent and mainly conduct monovalent cations with different selectivities [16]. A common inhibitor of Deg/ENaCs is the diuretic amiloride [16], ASICs and BASIC are also inhibited by diminazene, a diarylamidine that is used as an antiprotozoal drug in veterinary medicine $[7,37]$.

Shari Wiegreffe and Daniel Löhrer contributed equally to this work

Dominik Wiemuth

dwiemuth@ukaachen.de

1 Institute of Physiology, RWTH Aachen University, Pauwelsstrasse 30, 52074 Aachen, Germany
While the function of two subfamilies within the Deg/ $\mathrm{ENaC}$ family, the epithelial $\mathrm{Na}^{+}$channel $(\mathrm{ENaC})$ subfamily and the acid sensing ion channels (ASICs) subfamily, is well described [16], very little is known about the physiological role of BASIC. BASIC was originally named brainliver-intestine $\mathrm{Na}^{+}$channel (BLINaC) as it is predominantly expressed in the brain, liver, and intestinal tract [29]. More detailed analysis revealed expression in unipolar brush border cells of the cerebellum [5] and cholangiocytes, the epithelial cells lining bile ducts in the liver [38]. In UBCs, BASIC seems to be involved in intrinsic excitability [17], and the physiological function of BASIC in cholangiocytes, however, is not understood. Various bile acids activate BASIC robustly and reversibly in heterologous cell systems with various potencies but concentrations in the millimolar range are required for strong activation of BASIC [38, 22, 39]. The most potent effects were observed for hyodeoxycholic acid (HDCA) and ursodeoxycholic acid (UDCA) [39]. It has been proposed that BASIC is sensitive to alterations of its membrane environment and the mechanism of bile acid-dependent BASIC activation is based on a bile acidinduced modification of membrane properties, which in turn leads to an activation of the channel [30]. Concentrations of bile acids that activate BASIC in heterologous systems are 
reached in bile ducts; hence, a putative bile acid-dependent role for BASIC in the context of an electrolyte modification of the bile fluid can be assumed [38].

Cholangiocytes form the epithelial barrier of bile ducts in the liver. Like other epithelial cells, cholangiocytes are polarized and apical and basolateral plasma membrane regions execute multiple transport functions, which are relevant to bile formation and modification [3, 32]. Cholangiocytes are critical for generation and modification of the bile fluid and thus crucial for one of the liver's main functions, aiding digestion of fat by providing bile acids to the intestinal tract. Bile is a secretory fluid generated by the hepatobiliary system and contains a variety of components, e.g. bile acids, electrolytes, lipids, proteins, and endobiotic and xenobiotic compounds [3, 32]. Primary bile is generated by hepatocytes and secreted into the canalicular system of the liver. Subsequently, cholangiocytes regulate flow and composition of the bile $[3,32]$. One of the main mechanisms of bile flow regulation is the secretion of $\mathrm{HCO}_{3}{ }^{-}$to the ductal lumen [13]. This is achieved by an apically located interplay of $\mathrm{Cl}^{-}$secretion mediated by the cystic fibrosis conductance regulator (CFTR) and secretion of $\mathrm{HCO}_{3}{ }^{-}$in exchange with $\mathrm{Cl}^{-}$via the anion exchanger 2 (AE2) [2, 8, 10, 26, 33]. This process in turn drives the osmotic secretion of water via aquaporin 1 [25]. It is positively controlled by the hormone secretin [21] and inhibited by various other hormones, like somatostatin, gastrin, and endothelin $[6,11,12]$. Secretion of $\mathrm{HCO}_{3}{ }^{-}$leads to the formation of a so-called biliary bicarbonate umbrella, an alkaline barrier that renders bile acids deprotonated and thus polar and membrane impermeable $[14,34]$. Furthermore, bile contains several factors that also affect biliary secretion. Extracellular nucleotides activate P2Y receptors at the apical membrane [27], increasing cytosolic $\mathrm{Ca}^{2+}$ concentrations and thus enhance $\mathrm{Cl}^{-}$secretion through apical $\mathrm{Ca}^{2+}$-activated $\mathrm{Cl}^{-}$channels, such as transmembrane member 16A (TMEM16A; ANO1), a process that promotes $\mathrm{HCO}_{3}{ }^{-}$secretion [24]. Absorptive processes also occur in cholangiocytes; e.g., conjugated bile acids can be reabsorbed from the bile via an apical $\mathrm{Na}^{+}$-dependent bile salt transporter (ASBT) [18], and glucose can be absorbed by vectorial transport through the apical $\mathrm{Na}^{+}$-glucose cotransporter 1 (SGLT1) and the basolateral glucose transporter 1 (GLUT1), which provides an osmotic gradient that favors the reabsorption of water from bile [19]. $\mathrm{ENaC}$ is also found in cholangiocytes and reabsorbs $\mathrm{Na}^{+}$upon mechanical stimulation by bile flow [23]. The presence of other transport proteins and ion channels for example $\mathrm{P} 2 \mathrm{X}$ receptors $[9,41]$ suggests further complex regulatory mechanisms in cholangiocyte transport processes.

In this study, we have used a cultured cholangiocyte cell line derived from rat liver in a pharmacological and a gene knockout approach to unravel the physiological role of BASIC in bile duct physiology. We show that bile acids induce desensitizing transepithelial currents, which are partly mediated by BASIC. Thus, our study attributes for the first time a physiological role for BASIC in an epithelial cell type.

\section{Materials and methods}

\section{Cell culture}

Normal rat cholangiocytes (NRC) were a gift from Dr. Nicholas F. LaRusso (Mayo Clinic, College of Medicine, Rochester, Minnesota). Cells were grown on collagen-coated petri dishes (cell coat collagen Typ I, Greiner Bio One, Austria) in cholangiocyte growth medium as described previously [35].

\section{Immunocytochemistry}

Glass coverslips were coated with type I collagen from rat tail (Merck Sigma, Germany) and NRCs were seeded at a density of approximately $5 \times 10^{5}$ cells per $35 \mathrm{~mm}$ well and incubated for 13-17 days. NRCs were washed three times with PBS and fixed with PBS containing 4\% paraformaldehyde for at least $10 \mathrm{~min}$ at room temperature. Cells were washed twice with PBS and permeabilized by incubation with PBS containing $0.3 \%$ Triton-X-100 for $20 \mathrm{~min}$ at room temperature. Cells were washed three times with PBS and incubated with blocking solution containing $10 \%$ normal goat serum for $1 \mathrm{~h}$. Coverslips were transferred to a humidified chamber and incubated with a custom-made polyclonal anti-BASIC antibody from rabbit (Eurogentec, Belgium) (1:100 dilution) in blocking solution overnight at $4{ }^{\circ} \mathrm{C}$. Cells were washed three times with PBS and incubated with AlexaFluor ${ }^{\circledR}$ 488-conjugated anti-rabbit secondary antibody (1:500 dilution) for $1 \mathrm{~h}$ at $37^{\circ} \mathrm{C}$. To stain the nuclei, cells were incubated with PBS containing DAPI (1:5000 dilution) for $5 \mathrm{~min}$ at RT. After two washing steps, coverslips were dried and mounted in Mowiol (Merck Sigma, Germany). Stained cells were analyzed using a Zeiss LSM 700 confocal microscope (Carl Zeiss, Germany).

\section{Molecular biology and CRISPR-cas9 knockout strategy}

For the ablation of the BASIC gene, a CRISPR-cas9(D10A) paired nickase approach was used [28]. Briefly, two pX335B vectors, each containing two sgRNA coding sequences, were generated (sgRNAs: (1) CCAATATCAATAATTAGC TATGG, (2) GATTGCACTTAGGACTCTTGGGG, (3) CCAACGACAACATCTATAGAAGT, (4) TGTGGAGAA AATTGAGTTCCCGG). For selection of transfected cells, pX335B contains the coding sequence for GFP. Cells were transfected using XtremeGENE9 (Merck Sigma, Germany) 
and transfected cells were sorted by FACS (Flow Cytometry Facility, a core facility of the Interdisciplinary Center for Clinical Research (IZKF) Aachen within the Faculty of Medicine at RWTH Aachen University). Transfected cells were expanded, genomic DNA was isolated, and successful deletion of exon 2 was detected by PCR (genotyping primer: for TACATCCCCCTTTATTGCC', rev CCTGTTCAAGTT ACAGAATGTCA) and sequencing (Eurofins, Germany). For transcription analysis, mRNA from $\mathrm{NRC}^{\mathrm{BASIC}+/+}$ and $\mathrm{NRC}^{\mathrm{BASIC}-1-}$ cells was isolated using the RNeasy Mini Kit and cDNA was synthesized using the QuantiTect Reverse Transcription Kit (Qiagen, Germany) according to the manufacturer's instructions. Qualitative PCR was performed to show the presence or absence of BASIC and tubulin (control) mRNA (primer: BASIC for GCGAAGAAACAGAAT ACCCTGC, rev CTGTCTGAGGTGGAGAAGTCC; tubulin for CCAGGGCTTCTTGGTTTTCC, rev CGCTCAATG TCGAGGTTTCT).

\section{Ussing chamber experiments}

NRCs were seeded onto 12-mm Snapwell ${ }^{\mathrm{TM}}$ cell culture inserts (Corning Costar, Sigma-Aldrich, St. Louis, Mo, USA) at a density of approximately $5 \times 10^{5}$ cells per Snapwell ${ }^{\mathrm{TM}}$ and incubated for 13-17 days. Transepithelial electrical resistance (TEER) of NRC was measured daily using an Ohm voltmeter (Scientific Instruments, Aachen, Germany). Culture medium was exchanged every $48 \mathrm{~h}$ and $24 \mathrm{~h}$ prior to Ussing chamber measurements. After 13 days and when the TEER was $\geq 400 \Omega / \mathrm{cm}^{2}$, epithelia were mounted onto a modified Ussing chamber (Scientific Instruments, Aachen, Germany) stored in a $37{ }^{\circ} \mathrm{C}$ incubator. The Ussing chamber was connected to a 6-channel V/A clamp and data were recorded using the software CLAMP (Scientific Instruments, Aachen, Germany) running on a PC. Apical and basolateral surfaces were bathed in $1 \times$ Ringer's solution (in mM 140 $\mathrm{NaCl}, 4 \mathrm{KCl}, 2.4 \mathrm{KH}_{2} \mathrm{PO}_{4}, 1 \mathrm{CaCl}_{2}, 2 \mathrm{MgCl}_{2}, 10$ glucose, $\mathrm{pH}$ 7.4), kept at $37^{\circ} \mathrm{C}$. For low $\mathrm{Na}^{+}$experiments, apical and basolateral surfaces were bathed in $1 \times$ low $\mathrm{Na}^{+}$Ringer's solution (in mM $2.5 \mathrm{NaCl}, 137.5 \mathrm{NMDG}, 4 \mathrm{KCl}, 2.4$ $\mathrm{KH}_{2} \mathrm{PO}_{4}, 1 \mathrm{CaCl}_{2}, 2 \mathrm{MgCl}_{2}, 10$ glucose, $\mathrm{pH} 7.4$, adjusted with $\mathrm{HCl}$ ). Epithelia were measured in open-circuit configuration, transepithelial potential and resistance were measured every $20 \mathrm{~s}$, and transepithelial current was calculated according to Ohm's law. Peak amplitudes were determined as the difference in current recorded prior to the application of a substance to the apical bathing solution and the maximal current response after the application of a substance.

\section{Chemicals}

Diminazene, amiloride, taurochenodeoxycholic acid (CDCA), taurohyodeoxycholic acid (HDCA), and porcine bile extract (BE) were purchased from Sigma-Aldrich (Germany). Tauroursodeoxycholic (UDCA) acid was purchased from Merck (Germany).

\section{Data analysis and statistics}

Data were analyzed using the software Prism (GraphPad, San Diego, USA) and are presented as means \pm SEM. Statistical significance was calculated using Student's unpaired $t$ test.

\section{Results}

\section{Bile acids induce BASIC-dependent transepithelial currents}

To address whether BASIC is involved in ion transport processes in cholangiocytes, we used normal rat cholangiocytes (NRCs) [35]. NRCs maintained an epithelial-like, cholangiocyte phenotype when grown on cell culture inserts with 0.4$\mu \mathrm{m}$ pore size coated with rat tail collagen (Fig. 1A) and cells developed a moderate transepithelial electrical resistance (TEER) of approximately $400-600 \Omega / \mathrm{cm}^{2}$ after 2 weeks of culturing (Fig. 1B), which is in line with previous results [35]. Once the TEER of the NRC cell culture inserts had reached $400-600 \Omega / \mathrm{cm}^{2}$, Ussing chamber experiments were performed to measure transepithelial currents of the NRC epithelial layer in particular bile acid-induced currents. NRC epithelial layers exhibited a basal transepithelial current of $1 \pm 0.1 \mu \mathrm{A}$, which was insensitive to the BASIC blockers diminazene and amiloride (Fig. 1C/D). Cholangiocytes express purinergic $\mathrm{P} 2$ receptors, which stimulate $\mathrm{Cl}^{-}$secretion via TMEM16A [27, 24]. They provide a convenient way to assess the functionality of the NRC epithelium. Application of $100 \mu \mathrm{M}$ ATP to the apical side of an NRC epithelium typically resulted in a strong increase in transepithelial current of $7.2 \pm 0.4 \mu \mathrm{A}$ (Fig. 2A-D). The peak was reached after 2-3 min and current returned to baseline levels after 12-15 min (Fig. 2A-C). NRC layers not responding to ATP were not further included in experiments. Next, we applied pig bile extract (BE) to the apical lumen at a concentration $(30 \mathrm{mg} / \mathrm{ml})$ that is sufficient to strongly activate BASIC in Xenopus oocytes [38]. BE induced a strong increase in transepithelial current of $4.1 \pm 0.7 \mu \mathrm{A}$ (Fig. 2A/D). The peak was reached after 1-3 min and current returned to baseline after 5-7 min (Fig. 2A). In control experiments, in which only the vehicle solution was applied, no current increase was observed (data not shown). To test whether the BE-induced stimulation of transepithelial current was mediated by BASIC, the experiment was repeated in the presence of $100 \mu \mathrm{M}$ diminazene, an inhibitor of BASIC [37] (Fig. 2B/D). While the ATP-mediated response was 
Fig. 1 Cultured normal rat cholangiocytes (NRC) display an epithelial-like phenotype and develop a moderate transepithelial electrical resistance. A Phase-contrast microscopy shows the epithelial morphology of NRCs grown on cell culture inserts. Scale bar $=20 \mu \mathrm{m}$. B Average development of the transepithelial electrical resistance (TEER) of NRC epithelial layers over time. Day 0 represents seeding of cells on cell culture inserts. Cells were used for Ussing chamber experiments between day 13 and 16 (labeled in gray), $n=63$. C Repre-

sentative trace of transepithelial currents recorded from NRCs. Diminazene (DIMI) $(10 \mu \mathrm{M})$ was applied to the apical lumen at the indicated time. D Quantitative comparison of the basal transepithelial currents before and after application of $10 \mu \mathrm{M}$ DIMI or $10 \mu \mathrm{M}$ amiloride (AMI), $n=9$. Error bars $=$ SEM
A

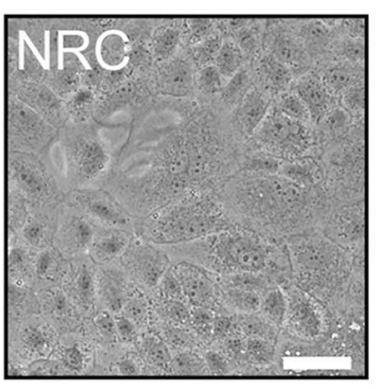

B

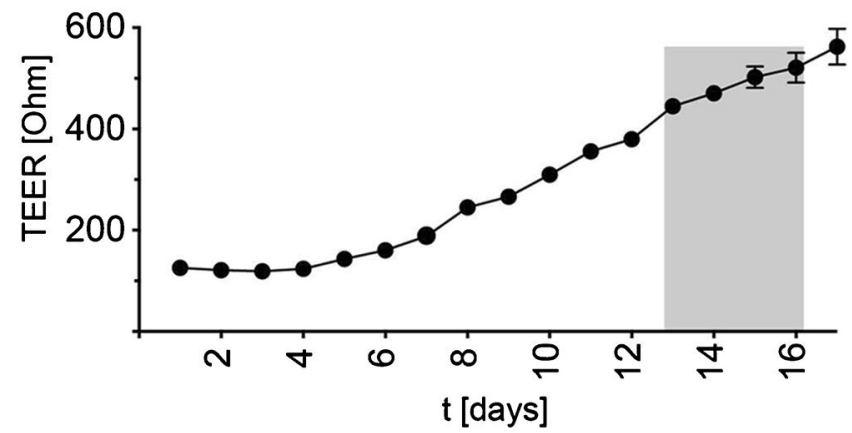

C

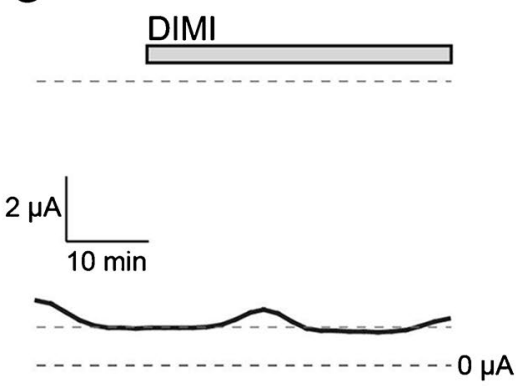

D

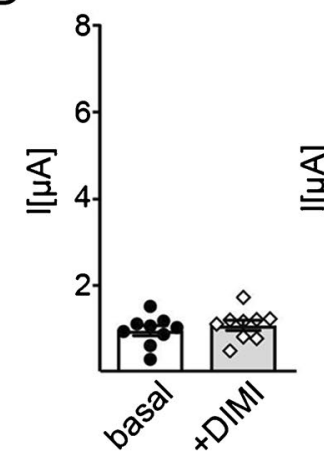

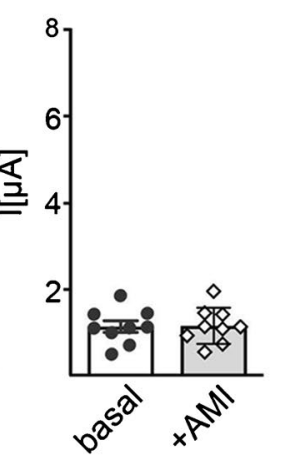

not affected by diminazene, the BE-induced response was significantly reduced to $1.7 \pm 0.4 \mu \mathrm{A}$ (Fig. $2 \mathrm{~B} / \mathrm{D}$ ), indicating that approximately $50 \%$ of the BE-induced transepithelial current is indeed mediated by BASIC. BE induced a similar diminazene-sensitive stimulation of transepithelial currents without prior application of ATP, albeit to a weaker extent $(3 \pm 0.3 \mu \mathrm{A})$ (Fig. $2 \mathrm{~F}-\mathrm{H})$.

Next, we repeated the experiments but applied purified bile acids instead of bile extract. Previous studies had shown that the combination of the two bile acids hyodeoxycholic acid (HDCA) and chenodeoxycholic acid (CDCA) was the most potent activator of BASIC [38, 39]. Therefore, we applied $1 \mathrm{mM}$ HDCA and $0.5 \mathrm{mM}$ CDCA to NRC epithelia. As expected, HDCA/CDCA induced similar responses as the bile extract $(3.8 \pm 0.6 \mu \mathrm{A})$ (Fig. 2E). Ursodeoxycholic acid (UDCA), another potent activator of BASIC, was also co-applied at $1 \mathrm{mM}$ with $0.5 \mathrm{mM}$ CDCA to NRC epithelia and also increased the transepithelial current albeit to a lower extent $(2.4 \pm 0.3 \mu \mathrm{A})$. A further increase in the UDCA concentration to $4 \mathrm{mM}$ did not increase the current further $(2.6 \pm 0.4 \mu \mathrm{A})$ (Fig. 2E), suggesting that a maximal activation of BASIC in NRC was already reached at $1 \mathrm{mM}$ UDCA. Furthermore, we confirmed the inhibition of the BE-induced current increase by diminazene also for the bile acids HDCA/CDCA (Fig. 2E).

BASIC is a cation channel with a slightly higher permeability for $\mathrm{Na}^{+}$over $\mathrm{K}^{+}$[36]. Under the ionic conditions of our experiments, activation of BASIC would mainly lead to $\mathrm{Na}^{+}$influx and thus to transepithelial currents similar to the ATP-induced $\mathrm{Cl}^{-}$efflux. To confirm that the bile acidinduced currents were indeed carried by $\mathrm{Na}^{+}$, we replaced the $\mathrm{Na}^{+}$in the apical solution by $\mathrm{NMDG}^{+}$, a cation that is not conducted by BASIC [36]. Interestingly the response of the NRC epithelial layer to bile acids was almost completely abolished (Fig. 2C/D), indicating that the bile acid-induced current is solely carried by $\mathrm{Na}^{+}$, consistent with a contribution of BASIC.

\section{Establishing a BASIC-deficient cholangiocyte cell line}

The pharmacological results indicate that BASIC is involved in ion transport processes. We aimed to verify these data using a cholangiocyte cell line, in which the BASIC gene is deleted and no BASIC protein is present anymore. To generate a BASIC knockout NRC cell line, we used the CRISPRcas9(D10A) gene editing system. We deleted a large portion of exon 2 and an adjacent intron region preceding exon 2 using a paired nickase approach, in which we designed 4 sgRNAs, which direct CRISPR-cas9(D10A) nickase to the regions of interests (Fig. 3A). Paired single strand breaks were induced and subsequently the region between these strand breaks was deleted [28]. As expected, our approach resulted in a 500-bp deletion as verified by genomic PCR (Fig. 3B) and sequencing. Successful knockout of BASIC was verified by RT-PCR. While in NRC WT a specific band 
Fig. 2 Bile acids induce BASIC-dependent transepithelial currents in NRCs. A Representative trace of transepithelial currents recorded from NRCs. ATP $(100 \mu \mathrm{M})$ and bile extract (BE, $30 \mathrm{mg} /$ $\mathrm{ml}$ ) were applied to the apical lumen at the indicated times. B As in A but for NRCs pretreated with $10 \mu \mathrm{M}$ diminazene. $\mathbf{C}$ As in $\mathbf{A}$ but extracellular $\mathrm{Na}^{+}$ was replaced by $\mathrm{NMDG}^{+}$. D Quantitative comparison of the peak amplitudes of the transepithelial currents induced by application of $100 \mu \mathrm{M}$ ATP or $\mathrm{BE}$ in the absence or presence of $10 \mu \mathrm{M}$ diminazene (DIMI). E Quantitative comparison of the peak amplitudes of the transepithelial currents induced by apical application of HDCA/ CDCA (1 mM/0.5 mM) or UDCA/CDCA $(1 \mathrm{mM} / 0.5 \mathrm{mM}$ and $4 \mathrm{mM} / 0.5 \mathrm{mM})$ or HDCA/ CDCA $(1 \mathrm{mM} / 0.5 \mathrm{mM})$ in the absence or presence of $10 \mu \mathrm{M}$ DIMI. F As in A but without application of ATP. G As in B but without application of ATP. H Quantitative comparison of the peak amplitudes of the transepithelial currents induced by application of BE in the absence or presence of $10 \mu \mathrm{M}$ DIMI. Error bars $=$ SEM, $n=8-9$, * indicates a significant difference to control at a level of $p<0.05$ or $* * p<0.01$
A

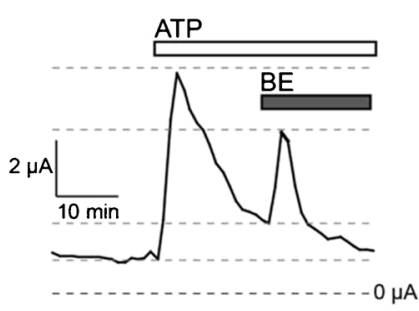

B

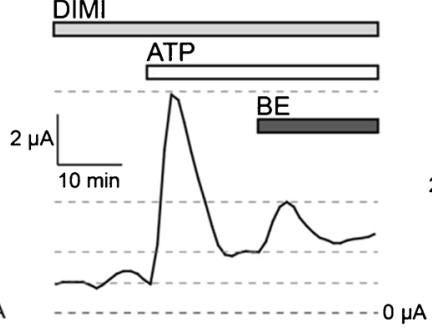

C
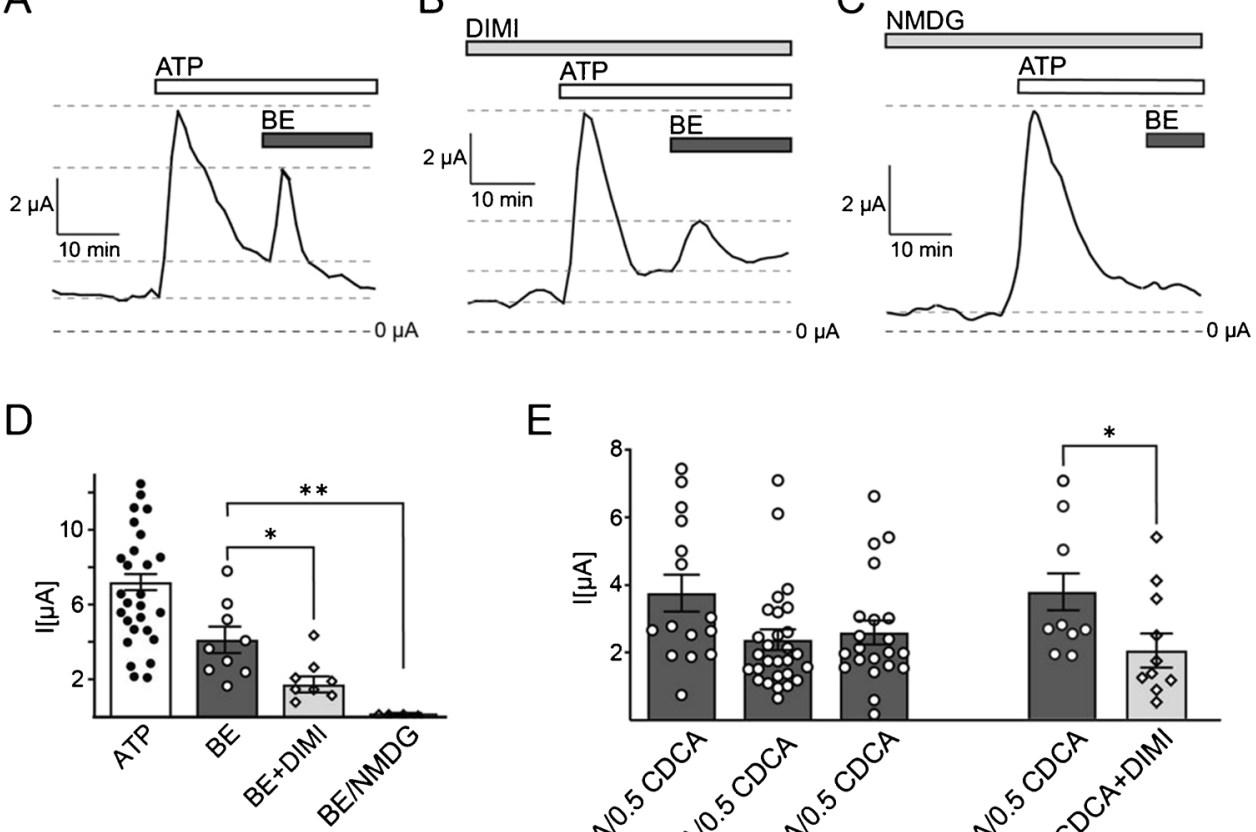

E

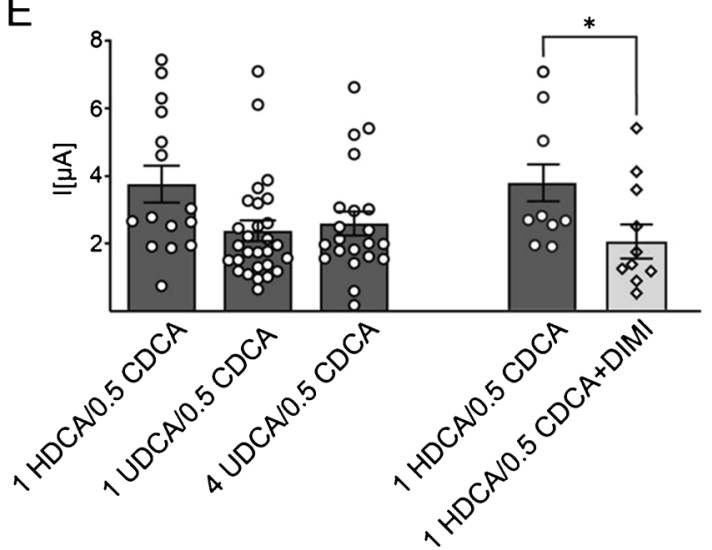

$\mathrm{F}$

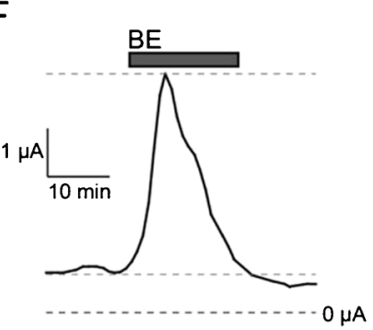

G

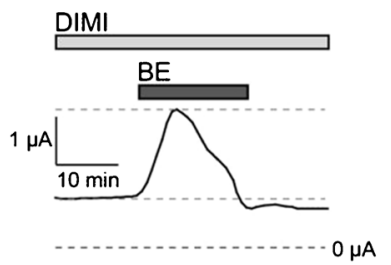

$\mathrm{H}$

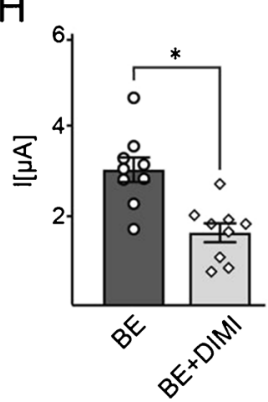

of the expected size was present, no BASIC mRNA was detectable in NRC KO cells (Fig. 3C). To further validate the knockout of BASIC, we performed immunostaining of cultured NRCs using a polyclonal anti-BASIC antibody. No expression of BASIC was detected in $\mathrm{NRC}^{\mathrm{BASIC}-/-}$ cells. In contrast, in $\mathrm{NRC}^{\mathrm{BASIC}+/+}$ cells, a punctate pattern of BASIC throughout the cytosol was detected (Fig. 3D). In summary, BASIC knockout cells were successfully generated by the CRISPR-cas9(D10A) system targeting exon 2.

\section{Bile acid-induced currents in cholangiocytes are partly carried by BASIC}

The NRC $\mathrm{BASIC-I-}^{\mathrm{B}}$ cells showed a normal cholangiocyte phenotype and a similar growth rate as $\mathrm{NRC}^{\mathrm{BASIC}+/+}$ cells. Of note, the development of the transepithelial electrical resistance of $\mathrm{NRC}^{\mathrm{BASIC}-1-}$ cells was only similar to NRC WT cells during the first 8 days but subsequently did not increase to the same extent (Fig. 4A). At days 13-16, the TEER of $\mathrm{NRC}^{\mathrm{BASIC}-1-}$ cells was approximately $125 \Omega / \mathrm{cm}^{2}$ lower compared with $\mathrm{NRC}^{\mathrm{BASIC}+/+}$ cells. This result indicates a putative role for BASIC under basal secretory conditions of cholangiocytes.

Next, we compared the effect of bile extract $(30 \mathrm{mg} / \mathrm{ml})$ between $\mathrm{NRC}^{\mathrm{BASIC}-/-}$ cells and $\mathrm{NRC}^{\mathrm{BASIC}+/+}$ cells. While the response to ATP was similar in both cell lines, the response to $\mathrm{BE}$ was drastically decreased in $\mathrm{NRC}^{\mathrm{BASIC}-/-}$ cells $\left(\mathrm{NRC}^{\mathrm{BASIC}+/+} 3 \pm 0.7 \mu \mathrm{A}, \mathrm{NRC}^{\mathrm{BASIC}-/-} 0.8 \pm 0.4 \mu \mathrm{A}\right)$ (Fig. 4B/C). This is in line with our finding that diminazene inhibited BE-dependent currents and shows that a large portion of the bile acid-induced response in cholangiocytes is indeed mediated by BASIC. The response to co-application of $1 \mathrm{mM}$ HDCA and $0.5 \mathrm{mM}$ CDCA was similarly reduced in NRC ${ }^{\text {BASIC-I- }}$ cells (Fig. 4D/E). Next, we tested the inhibitory effect of diminazene and amiloride, another specific Deg/ENaC inhibitor, on bile acid-induced 

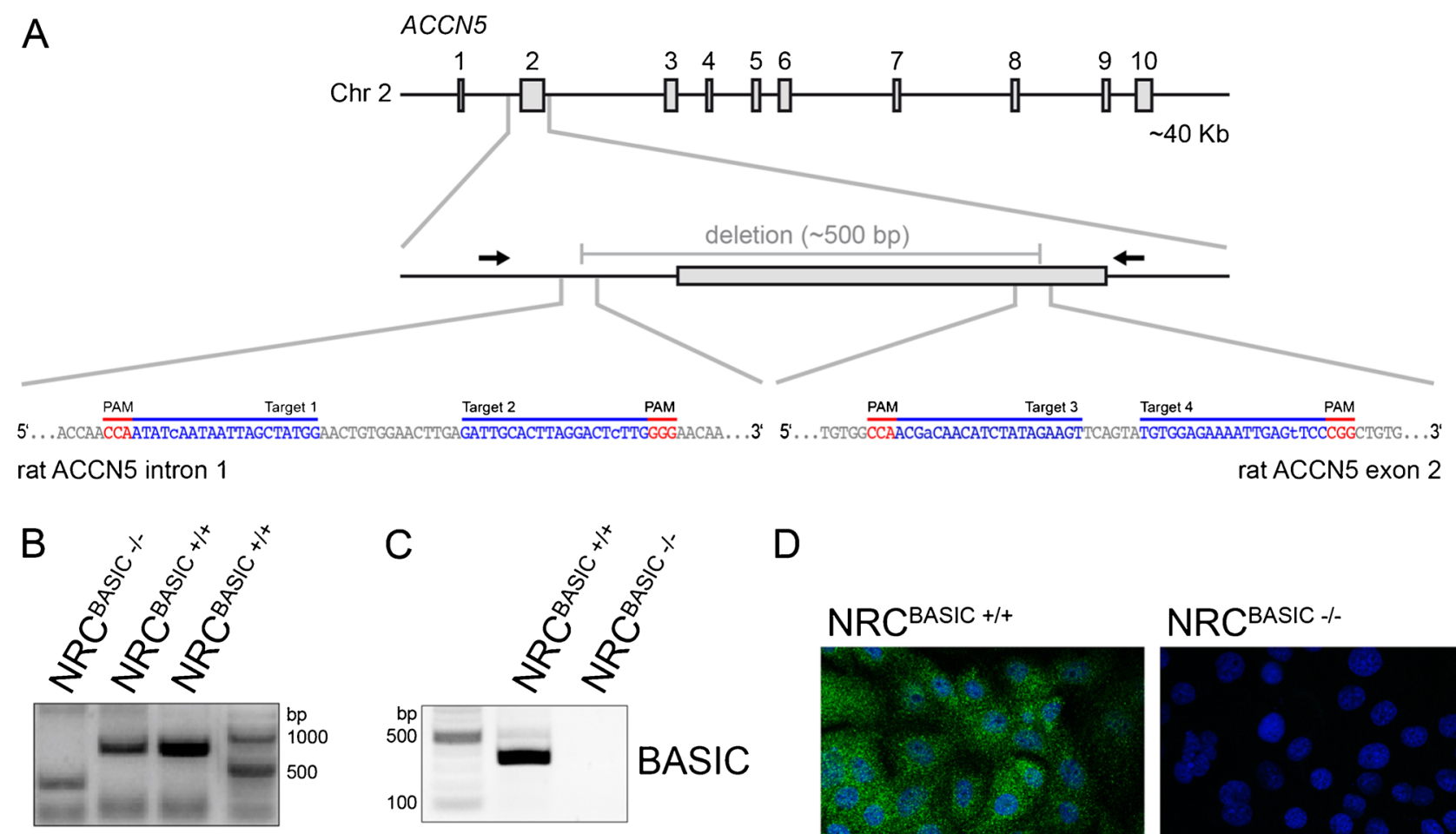

D
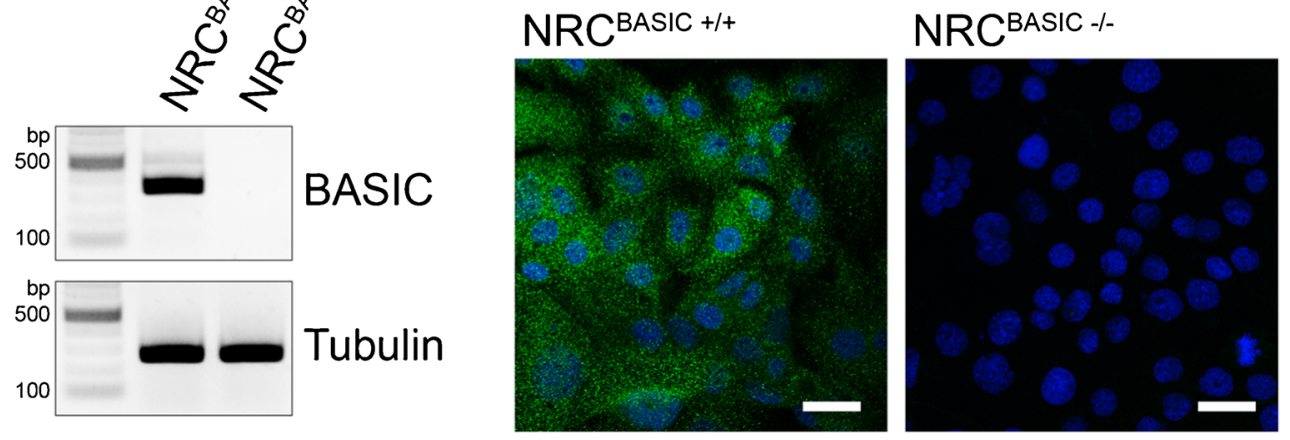

Fig. 3 Specific CRISPR Cas9(D10A) paired nickase-mediated knockout of BASIC. A Scheme of the CRISPR-Cas9-D10A paired nickase approach for the genomic ablation of BASIC in NRCs, blue: sgRNAs, red: PAM motif, arrows: primer position for genomic PCR. B Genomic control PCR showing the deletion of a 500-bp fragment

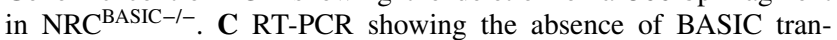

currents in $\mathrm{NRC}^{\mathrm{BASIC}-1-}$ and $\mathrm{NRC}^{\mathrm{BASIC}+/+}$ cells. While in $\mathrm{NRC}^{\mathrm{BASIC}+/+}$ cells the presence of diminazene and amiloride decreased the bile acid-dependent current drastically in $\mathrm{NRC}^{\mathrm{BASIC-l}-}$ cells, the bile acid-dependent current was not decreased by either diminazene or amiloride.

Taken together, these data from our pharmacological and BASIC knockout experiments show that in cholangiocytes, bile acids induce a current which is partly mediated by BASIC.

\section{Discussion}

In recent years, some progress has been made in understanding how BASIC can be activated and what the underlying mechanism is. Moreover, pharmacological tools have been identified and the sites of expression were described in detail $[37,5,38,39,30]$. However, the physiological function of the channel remains puzzling. Bile acids have been shown to be natural activators of BASIC [38, 39] but whether this

script in $\mathrm{NRC}^{\mathrm{BASIC}-/-}$. D Immunofluorescence staining for BASIC in $\mathrm{NRC}^{\mathrm{BASIC+/+}}$ and $\mathrm{NRC}^{\mathrm{BASIC}-/-}$. Paraffin-fixed cells were permeabilized and stained with polyclonal rabbit anti-BASIC antibody and AlexaFluor488 secondary anti-rabbit antibody. Blue: nuclei, scale bar: $20 \mu \mathrm{m}$

mode of activation is of any physiological relevance also remains an open question. Cholangiocytes are probably the cell type that is in contact with the highest possible concentrations of bile acids in the body. Here we show that in a cholangiocyte cell line, BASIC is partly responsible for bile acid-induced transepithelial currents, suggesting that it is involved in epithelial transport processes in bile ducts.

We have made two approaches to study the role of BASIC in cholangiocytes: We used pharmacological tools, namely bile acids as activators and diminazene and amiloride as inhibitors, and a CRISPR-cas9(D10A)-based knockout strategy to show that BASIC contributes to transepithelial currents elicited by bile acids. Application of millimolar concentrations of various bile acids induced transepithelial current, which is in line with previous findings [38], and diminazene and amiloride decreased these currents to approximately $50 \%$. In heterologous expression systems, the onset of the BASIC response to bile acids is faster than in cholangiocytes, which may be explained by either a slower application of bile acids or additional cellular components 
Fig. 4 Bile acid-induced currents in normal rat cholangiocytes are mediated partly by BASIC. A Average development of the transepithelial electrical resistance (TEER) of $\mathrm{NRC}^{\mathrm{BASIC+/+}}$ (closed circles, data from Fig. 1B) and $\mathrm{NRC}^{\mathrm{BASIC}-1-}$ (open circles) epithelial layers over time. Error bars represent the SEM, $n=63$. B Representative traces of transepithelial currents recorded from $\mathrm{NRC}^{\mathrm{BASIC}+/+}$ (left panel) and $\mathrm{NRC}^{\mathrm{BASIC}-1-}$ (right panel). $\operatorname{ATP}(100 \mu \mathrm{M})$ and BE $(30 \mathrm{mg} /$ $\mathrm{ml})$ were applied to the apical lumen at the indicated times. $\mathbf{C}$ Quantitative comparison of the peak amplitudes of the transepithelial current increases induced by apical application of BE to $\mathrm{NRC}^{\mathrm{BASIC}+1+}$ and NRC $\mathrm{NASIC-l-}^{\text {. }}$

D Quantitative comparison of the peak amplitudes of the transepithelial current increases induced by apical application of $1 \mathrm{mM}$ HDCA and $0.5 \mathrm{mM}$ CDCA to $\mathrm{NRC}^{\mathrm{BASIC}+/+}$ and $\mathrm{NRC}^{\mathrm{BASIC}-1-}$ in the absence or presence of $10 \mu \mathrm{M}$ diminazene (+DIMI). E As in D but with $1 \mathrm{mM}$ UDCA and $0.5 \mathrm{mM}$ CDCA and in the absence or presence of $10 \mu \mathrm{M}$ amiloride $(+$ AMI $)$. Error bars $=$ SEM, $n=9$, * indicates a significant difference to control at a level of $p<0.05$ or $* * p<0.01$

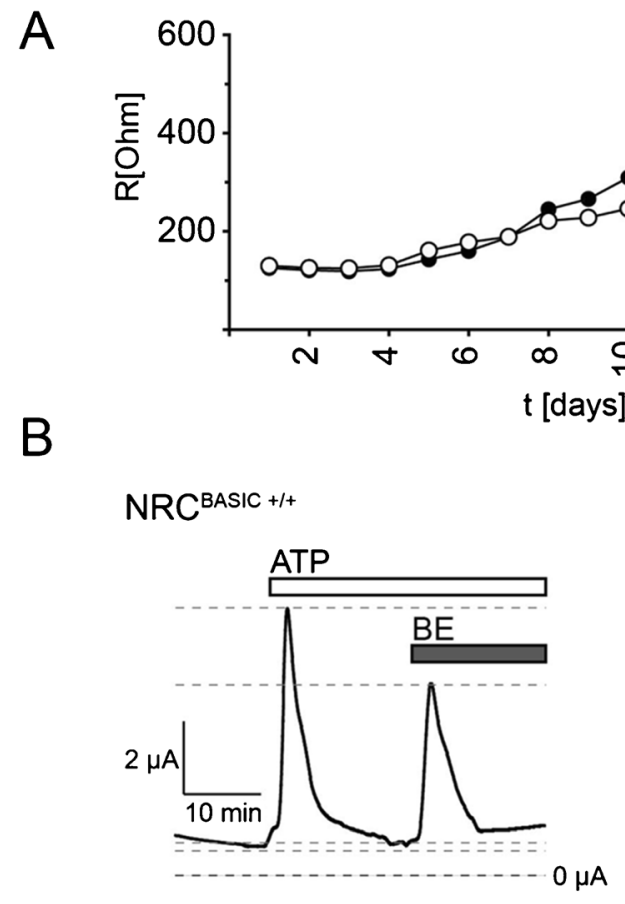

NRCBASIC -

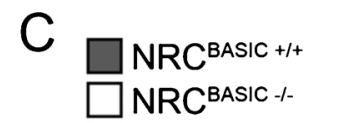

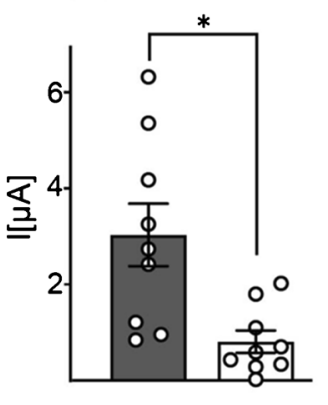

BE

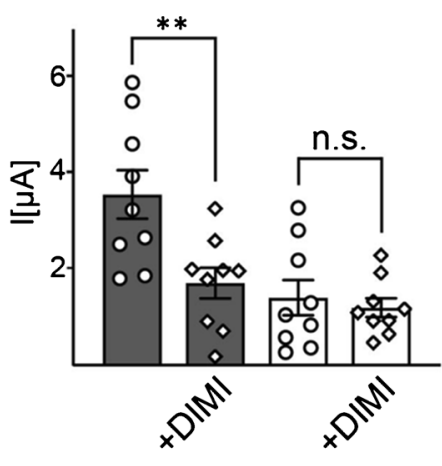

1 HDCAV 0.5 CDCA

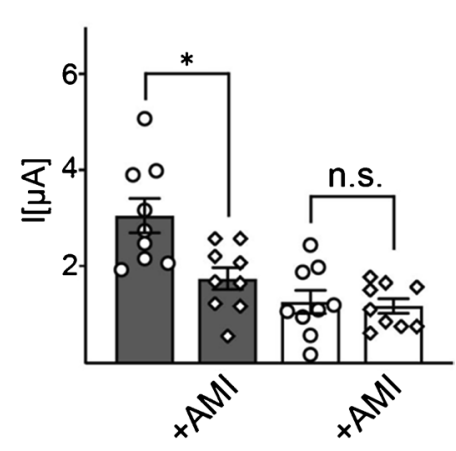

4.5 UDCA/0.5 CDCA that affect BASIC currents in these cells. Furthermore, the bile acid response in cholangiocytes is only transient, which is also in contrast to BASIC currents in heterologous expression systems [38]. It will be interesting to investigate these apparent differences in detail. Ablation of BASIC in cholangiocytes reduced the bile acid-induced currents to the same extent. These findings indicate that approximately $50 \%$ of this current is indeed conducted by BASIC. Furthermore, our results demonstrate that the bile acid-induced current is mainly carried by $\mathrm{Na}^{+}$, which is in line with a cationselective channel like BASIC. The remaining $50 \%$ of the bile acid-mediated current is BASIC-independent and thus carried by other transport mechanisms. We speculate that for example the electrogenic absorption of glucose via the
$\mathrm{Na}^{+}$-dependent glucose transporter SGLT1 [19] or the activation of $\mathrm{Na}^{+}$-conducting P2X receptors [9] may contribute to this bile acid-mediated current.

The main task of cholangiocytes is to guarantee a continuous flow of bile with all its compounds towards the gallbladder and the duodenum. This is achieved by secretion of $\mathrm{HCO}_{3}{ }^{-}$, which is followed by an osmotically driven efflux of water [32]. How does $\mathrm{Na}^{+}$absorption fit into this picture? Interestingly, it was shown that $\mathrm{ENaC}$ is also expressed in mouse biliary epithelial cells. Here it absorbs $\mathrm{Na}^{+}$upon increased mechanical stress induced by high bile flow rates, which leads to water absorption thereby decreasing bile flow again [23]. In a scenario where high bile flow with high concentrations of bile acids occurs, BASIC, as a sensor for high 
Fig. 5 Possible role of BASIC in cholangiocyte ion transport. Bile acids (BA) activate BASIC. This leads to an increase of the intracellular $\mathrm{Na}^{+}$concentration and in turn results in an increase in $\mathrm{HCO}_{3}{ }^{-}$secretion via $\mathrm{NBC} 4 \mathrm{c}$ and a decrease in $\mathrm{H}^{+}$secretion via NHE

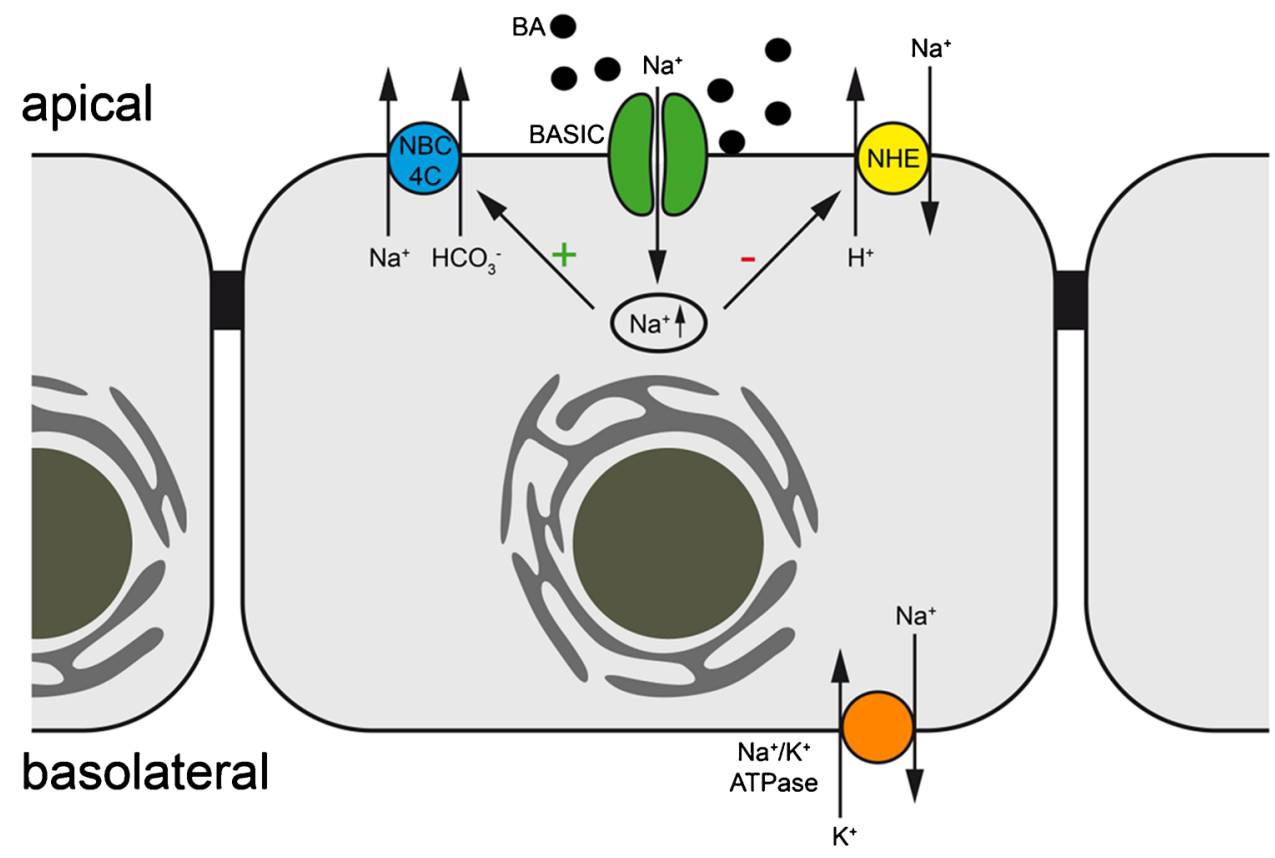

concentrations of bile acids, may aid $\mathrm{ENaC}$ in responding to a high bile flow and reduce flow by $\mathrm{Na}^{+}$absorption and subsequent water reabsorption.

What other implications could a bile acid-dependent absorption of $\mathrm{Na}^{+}$in cholangiocytes have? $\mathrm{HCO}_{3}{ }^{-}$secretion is one of the most important tasks of cholangiocytes und guarantees an adequate bile flow [32, 13, 2]; furthermore, the secreted $\mathrm{HCO}_{3}{ }^{-}$forms the so-called $\mathrm{HCO}_{3}{ }^{-}$umbrella [14], which, together with the glycocalyx of cholangiocytes, is important for cholangiocyte protection as it keeps bile acids that are in close proximity to the cell membrane deprotonated and thus less toxic for the cells as polar bile acids cannot permeate through the cell membrane [14]. The anion exchanger 2 (AE2) is responsible for the vast majority of $\mathrm{HCO}_{3}^{-}$secretion in cholangiocytes and it uses the $\mathrm{Cl}^{-}$gradient as a driving force [32]. In rat cholangiocytes, a subtype of $\mathrm{Na}^{+}-\mathrm{HCO}_{3}{ }^{-}$cotransporter (NBC), $\mathrm{NBC} 4 \mathrm{c}$, was found at the apical membrane [1]. Expressed at the apical membrane, it could allow further $\mathrm{HCO}_{3}^{-}$secretion if enough intracellular $\mathrm{Na}^{+}$would be present to drive $\mathrm{Na}^{+}$and $\mathrm{HCO}_{3}{ }^{-}$secretion. A BASIC-driven accumulation of $\mathrm{Na}^{+}$at the intracellular side of the apical membrane could thus increase the secretion of $\mathrm{HCO}_{3}{ }^{-}$(Fig. 5) and lead to a strengthening of the protective $\mathrm{HCO}_{3}{ }^{-}$umbrella, which would be especially important if bile acid concentration in the bile ducts would increase.

Cholangiocytes also express different $\mathrm{Na}^{+}-\mathrm{H}^{+}$exchanger (NHE) at their apical and basolateral membrane, which are crucial for maintaining the intracellular $\mathrm{pH}$ as they allow secretion of $\mathrm{H}^{+}$in exchange with $\mathrm{Na}^{+}$[31]. To guarantee the proper protective function of the $\mathrm{HCO}_{3}{ }^{-}$umbrella, however, it is important to tightly control the apical $\mathrm{H}^{+}$ secretion via NHEs. A BASIC-mediated accumulation of $\mathrm{Na}^{+}$in the apical compartment of the cell would decrease the driving force for $\mathrm{H}^{+}$secretion by NHEs, when bile acid concentrations are high (Fig. 5), and would thus maintain the alkaline $\mathrm{pH}$ of the bile fluid and protect the epithelium from bile acids. This could represent another possible role for BASIC in cholangiocyte physiology.

Small amounts of bile acids can be reabsorbed by cholangiocytes from intrahepatic bile ducts and returned back to hepatocytes via the cholehepatic shunt pathway, which provides a recycling pathway for bile acids and may be involved in several processes where bile acids play a role e.g. gene expression, second messenger regulation, and modulation of ion transport processes [32, 42]. While unconjugated bile acids can passively diffuse through the apical membrane of cholangiocytes, conjugated bile acids are reabsorbed by the $\mathrm{Na}^{+}$-dependent bile acid transporter SLC10A2 [20]. We speculate that the bile aciddependent increase in $\mathrm{Na}^{+}$absorption mediated by BASIC may decrease the driving force for $\mathrm{Na}^{+}$and consequently lower the amount of bile acids that can be reabsorbed via SLC10A2. Thus, BASIC might affect indirectly the cholehepatic shunt pathway.

Taken together, our data suggest that BASIC plays a regulatory role in fine-tuning ion transport by rat cholangiocytes.

Acknowledgements We thank Stefan Gründer for helpful discussions and comments on the manuscript.

Author contribution All authors contributed to the study conception and design. Material preparation, data collection, and analysis were performed by Shari Wiegreffe, Daniel Löhrer Monika Wirtz, and 
Dominik Wiemuth. The first draft of the manuscript was written by Dominik Wiemuth and all authors commented on previous versions of the manuscript. All authors read and approved the final manuscript.

Funding Open Access funding enabled and organized by Projekt DEAL. This project was supported by the START program of the Faculty of Medicine of RWTH Aachen University and a DFG grant to DW (WI 4176/1-1).

Availability of data and material This manuscript has no associated data. All data are contained within the manuscript. Cell lines are available upon request.

Code availability Not applicable.

\section{Declarations}

Competing interests The authors declare no competing interests.

Open Access This article is licensed under a Creative Commons Attribution 4.0 International License, which permits use, sharing, adaptation, distribution and reproduction in any medium or format, as long as you give appropriate credit to the original author(s) and the source, provide a link to the Creative Commons licence, and indicate if changes were made. The images or other third party material in this article are included in the article's Creative Commons licence, unless indicated otherwise in a credit line to the material. If material is not included in the article's Creative Commons licence and your intended use is not permitted by statutory regulation or exceeds the permitted use, you will need to obtain permission directly from the copyright holder. To view a copy of this licence, visit http://creativecommons.org/licenses/by/4.0/.

\section{References}

1. Abuladze N, Pushkin A, Tatishchev S, Newman D, Sassani P, Kurtz I (2004) Expression and localization of rat NBC4c in liver and renal uroepithelium. Am J Physiol Cell Physiol 287:C781C789. https://doi.org/10.1152/ajpcell.00590.2003

2. Banales JM, Arenas F, Rodriguez-Ortigosa CM, Saez E, Uriarte I, Doctor RB, Prieto J, Medina JF (2006) Bicarbonate-rich choleresis induced by secretin in normal rat is taurocholate-dependent and involves AE2 anion exchanger. Hepatology 43:266-275. https://doi.org/10.1002/hep.21042

3. Banales JM, Huebert RC, Karlsen T, Strazzabosco M, LaRusso NF, Gores GJ (2019) Cholangiocyte pathobiology. Nat Rev Gastroenterol Hepatol 16:269-281. https://doi.org/10.1038/ s41575-019-0125-y

4. Bartoi T, Augustinowski K, Polleichtner G, Gründer S, Ulbrich MH (2014) Acid-sensing ion channel (ASIC) 1a/2a heteromers have a flexible 2:1/1:2 stoichiometry. Proc Natl Acad Sci USA 111:8281-8286. https://doi.org/10.1073/pnas.1324060111

5. Boiko N, Kucher V, Wang B, Stockand JD (2014) Restrictive expression of acid-sensing ion channel 5 (asic5) in unipolar brush cells of the vestibulocerebellum. PLoS ONE 9:e91326. https://doi. org/10.1371/journal.pone.0091326

6. Caligiuri A, Glaser S, Rodgers RE, Phinizy JL, Robertson W, Papa E, Pinzani M, Alpini G (1998) Endothelin-1 inhibits secretinstimulated ductal secretion by interacting with ETA receptors on large cholangiocytes. Am J of Physiol Gastrointest Liver Physiol 275:G835-G846. https://doi.org/10.1152/ajpgi.1998.275.4.G835
7. Chen XM, Qiu LY, Li MH, Dürrnagel S, Orser BA, Xiong ZG, MacDonald JF (2010) Diarylamidines: high potency inhibitors of acid-sensing ion channels. Neuropharmacology 58:1045-1053. https://doi.org/10.1016/j.neuropharm.2010.01.011

8. Cohn JA, Strong TV, Picciotto MR, Nairn AC, Collins FS, Fitz JG (1993) Localization of the cystic fibrosis tansmembrane conductance regulator in human bile duct epithelial cells. Gastroenterology 105:1857-1864. https://doi.org/10.1016/0016-5085(93) 91085-V

9. Doctor RB, Matzakos T, McWilliams R, Johnson S, Feranchak AP, Fitz JG (2005) Purinergic regulation of cholangiocyte secretion: identification of a novel role for $\mathrm{P} 2 \mathrm{X}$ receptors. Am $\mathrm{J}$ of Physiol Gastrointest Liver Physiol 288:G779-G786. https://doi. org/10.1152/ajpgi.00325.2004

10. Fitz JG, Basavappa S, Mcgill J, Melhus O, Cohn JA (1993) Regulation of membrane chloride currents in rat bile duct epithelial cells. J Clin Invest 91:319-328. https://doi.org/10.1172/ Jci116188

11. Glaser SS, Rodgers RED, Phinizy JL, Robertson WE, Lasater J, Caligiuri A, Tretjak Z, LeSage GD, Alpini G (1997) Gastrin inhibits secretin-induced ductal secretion by interaction with specific receptors on rat cholangiocytes. Am J of Physiol Gastrointest Liver Physiol 273:G1061-G1070. https://doi.org/10.1152/ajpgi. 1997.273.5.G1061

12. Gong AY, Tietz PS, Muff MA, Splinter PL, Huebert RC, Strowski MZ, Chen XM, LaRusso NF (2003) Somatostatin stimulates ductal bile absorption and inhibits ductal bile secretion in mice via SSTR2 on cholangiocytes. Am J Physiol Cell Physiol 284:C1205C1214. https://doi.org/10.1152/ajpcell.00313.2002

13. Hardison WGM, Wood CA (1978) Importance of bicarbonate in bile salt independent fraction of bile flow. Am J Physiol 235:E158-E164. https://doi.org/10.1152/ajpendo.1978.235.2. E158

14. Hohenester S, Wenniger LMD, Paulusma CC, van Vliet SJ, Jefferson DM, Elferink RPO, Beuers U (2012) A biliary HCO3umbrella constitutes a protective mechanism against bile acidinduced injury in human cholangiocytes. Hepatology 55:173-183. https://doi.org/10.1002/hep.24691

15. Jasti J, Furukawa H, Gonzales EB, Gouaux E (2007) Structure of acid-sensing ion channel 1 at 1.9A resolution and low $\mathrm{pH}$. Nature 449:316-323. https://doi.org/10.1038/nature06163

16. Kellenberger S, Schild L (2015) International Union of Basic and Clinical Pharmacology. XCI. Structure, function, and pharmacology of acid-sensing ion channels and the epithelial $\mathrm{Na}+$ channel. Pharmacol Rev 67:1-35

17. Kreko-Pierce T, Boiko N, Harbidge DG, Marcus DC, Stockand JD, Pugh JR (2020) Cerebellar ataxia caused by type II unipolar brush cell dysfunction in the Asic5 knockout mouse. Sci Rep 10(1):2168. https://doi.org/10.1038/s41598-020-58901-y

18. Kullak-Ublick GA, Stieger B, Meier PJ (2004) Enterohepatic bile salt transporters in normal physiology and liver disease. Gastroenterology 126:322-342. https://doi.org/10.1053/j.gastro.2003.06. 005

19. Lazaridis KN, Pham L, Vroman B, deGroen PC, LaRusso NF (1997) Kinetic and molecular identification of sodium-dependent glucose transporter in normal rat cholangiocytes. Am J of Physiol Gastrointest Liver Physiol 272:G1168-G1174. https://doi.org/10. 1152/ajpgi.1997.272.5.G1168

20. Lazaridis KN, Pham L, Tietz P, Marinelli PA, deGroen PC, Levine S, Dawson PA, LaRusso NF (1997) Rat cholangiocytes absorb bile acids at their apical domain via the ileal sodium-dependent bile acid transporter. J Clin Invest 100:2714-2721. https://doi.org/10. 1172/JCI119816

21. Lenzen R, Alpini G, Tavoloni N (1992) Secretin stimulates bile ductular secretory activity through the cAMP System. Am J 
Physiol 263:G527-G532. https://doi.org/10.1152/ajpgi.1992. 263.4.G527

22. Lenzig P, Wirtz M, Wiemuth D (2019) Comparative electrophysiological analysis of the bile acid-sensitive ion channel (BASIC) from different species suggests similar physiological functions. Pflügers Arch 471:329-336. https://doi.org/10.1007/ s00424-018-2223-z

23. Li Q, Kresge C, Bugde A, Lamphere M, Park JY, Feranchak AP (2016) Regulation of mechanosensitive biliary epithelial transport by the epithelial Na+ channel. Hepatology 63:538-549. https:// doi.org/10.1002/hep. 28301

24. Li Q, Dutta A, Kresge C, Bugde A, Feranchak AP (2018) Bile acids stimulate cholangiocyte fluid secretion by activation of transmembrane member 16A Cl- channels. Hepatology 68:187199. https://doi.org/10.1002/hep.29804

25. Marinelli RA, Tietz PS, Pham LD, Rueckert L, Agre P, LaRusso NF (1999) Secretin induces the apical insertion of aquaporin-1 water channels in rat cholangiocytes. Am J of Physiol Gastrointest Liver Physiol 276:G280-G286. https://doi.org/10.1152/ajpgi. 1999.276.1.G280

26. Martinezanso E, Castillo JE, Diez J, Medina JF, Prieto J (1994) Immunohistochemical detection of chloride/bicarbonate anionexchangers in human liver. Hepatology 19:1400-1406. https:// doi.org/10.1002/hep.1840190613

27. Masyuk AI, Gradilone SA, Banales JM, Huang BQ, Masyuk TV, Lee SO, Splinter PL, Stroope AJ, LaRusso NF (2008) Cholangiocyte primary cilia are chemosensory organelles that detect biliary nucleotides via P2Y(12) purinergic receptors. Am J of Physiol Gastrointest Liver Physiol 295:G725-G734. https://doi.org/10. 1152/ajpgi.90265.2008

28. Ran FA, Hsu PD, Lin CY, Gootenberg JS, Konermann S, Trevino AE, Scott DA, Inoue A, Matoba S, Zhang Y, Zhang F (2013) Double nicking by RNA-guided CRISPR Cas9 for enhanced genome editing specificity. Cell 154:1380-1389. https://doi.org/10.1016/j. cell.2013.09.040

29. Sakai H, Lingueglia E, Champigny G, Mattei MG, Lazdunski M (1999) Cloning and functional expression of a novel degenerinlike $\mathrm{Na}+$ channel gene in mammals. J Physiol 519:323-333. https://doi.org/10.1111/j.1469-7793.1999.0323m.x

30. Schmidt A, Lenzig P, Oslender-Bujotzek A, Kusch J, Lucas SD, Gründer S, Wiemuth D (2014) The bile acid-sensitive ion channel (BASIC) is activated by alterations of its membrane environment. PLoS ONE 9:e111549. https://doi.org/10.1371/journal. pone. 0111549

31. Spirli C, Granato A, Zsembery A, Anglani F, Okolicsanyi L, LaRusso NF, Crepaldi G, Strazzabosco M (1998) Functional polarity of $\mathrm{Na}+/ \mathrm{H}+$ and $\mathrm{Cl}-/ \mathrm{HCO} 3$ - in a rat cholangiocyte cell line. Am J of Physiol Gastrointest Liver Physiol 275:G1236G1245. https://doi.org/10.1152/ajpgi.1998.275.6.G1236
32. Tabibian JH, Masyuk AI, Masyuk TV, O'Hara SP, LaRusso NF (2013) Physiology of cholangiocytes Compr Physiol 3:541-565. https://doi.org/10.1002/cphy.c120019

33. Uriarte I, Banales JM, Saez E, Arenas F, Elferink RPJO, Prieto J, Medina JF (2010) Bicarbonate secretion of mouse cholangiocytes involves $\mathrm{Na}+\mathrm{HCO} 3$ - cotransport in addition to $\mathrm{Na}$-independent Cl-/HCO3- exchange. Hepatology 51:891-902. https://doi.org/10. 1002/hep.23403

34. van Niekerk J, Kersten R, Beuers U (2018) Role of bile acids and the biliary $\mathrm{HCO}$ - umbrella in the pathogenesis of primary biliary cholangitis. Clin Liver Dis 22:457-479. https://doi.org/10.1016/j. cld.2018.03.013

35. Vroman B, LaRusso NF (1996) Development and characterization of polarized primary cultures of rat intrahepatic bile duct epithelial cells. Lab Invest 74:303-313

36. Wiemuth D, Gründer S (2010) A single amino acid tunes Ca2+ inhibition of brain liver intestine $\mathrm{Na}+$ channel (BLINaC). J Biol Chem 285:30404-30410. https://doi.org/10.1074/jbc.M110. 153064

37. Wiemuth D, Gründer S (2011) The pharmacological profile of brain liver intestine $\mathrm{Na}+$ channel: inhibition by diarylamidines and activation by fenamates. Mol Pharmacol 80:911-919. https:// doi.org/10.1124/mol.111.073726

38. Wiemuth D, Sahin H, Falkenburger BH, Lefevre CM, Wasmuth HE, Gründer S (2012) BASIC - a bile acid-sensitive ion channel highly expressed in bile ducts. FASEB J 26:4122-4130. https:// doi.org/10.1096/fj.12-207043

39. Wiemuth D, Sahin H, Lefevre CM, Wasmuth HE, Gründer S (2013) Strong activation of bile acid-sensitive ion channel (BASIC) by ursodeoxycholic acid. Channels (Austin) 7:38-42. https://doi.org/10.4161/chan.22406

40. Wiemuth D, Assmann M, Gründer S (2014) The bile acid-sensitive ion channel (BASIC), the ignored cousin of ASICs and ENaC. Channels 8:29-34. https://doi.org/10.4161/chan.27493

41. Woo K, Sathe M, Kresge C, Esser V, Ueno Y, Venter J, Glaser SS, Alpini G, Feranchak AP (2010) Adenosine triphosphate release and purinergic $(\mathrm{P} 2)$ receptor-mediated secretion in small and large mouse cholangiocytes. Hepatology 52:1819-1828. https://doi.org/ 10.1002/hep. 23883

42. Xia XF, Francis H, Glaser S, Alpini G, LeSage G (2006) Bile acid interactions with cholangiocytes. World J Gastroenterol 12:35533563. https://doi.org/10.3748/wjg.v12.i22.3553

Publisher's note Springer Nature remains neutral with regard to jurisdictional claims in published maps and institutional affiliations. 